\title{
Alpha-1 adrenoceptor hyperresponsiveness in three neuropathic pain states: Complex regional pain syndrome 1, diabetic peripheral neuropathic pain and central pain states following spinal cord injury
}

\author{
Robert W Teasell MD FRCPC $1,3,4,5$, J Malcolm O Arnold MD FRCPC 2,3,4,6
}

RW Teasell, JMO Arnold. Alpha-1 adrenoceptor hyperresponsiveness in three neuropathic pain states: Complex regional pain syndrome 1 , diabetic peripheral neuropathic pain and central pain states following spinal cord injury. Pain Res Manage 2004;9(2):89-97.

The pathophysiology of the pain associated with complex regional pain syndrome, spinal cord injury and diabetic peripheral neuropathy is not known. The pain of complex regional pain syndrome has often been attributed to abnormal sympathetic nervous system activity based on the presence of vasomotor instability and a frequently reported positive response, albeit a temporary response, to sympathetic blockade. In contrast, the pain below the level of spinal cord injury and diabetic peripheral neuropathy are generally seen as deafferentation phenomena. Each of these pain states has been associated with abnormal sympathetic nervous system function and increased peripheral alpha-1 adrenoceptor activity. This increased responsiveness may be a consequence of alpha- 1 adrenoceptor postsynaptic hypersensitivity, or alpha-2 adrenoceptor presynaptic dysfunction with diminished noradrenaline reuptake, increased concentrations of noradrenaline in the synaptic cleft and increased stimulation of otherwise normal alpha-1 adrenoceptors. Plausible mechanisms based on animal research by which alpha-1 adrenoceptor hyperresponsiveness can lead to chronic neuropathic-like pain have been reported. This raises the intriguing possibility that sympathetic nervous system dysfunction may be an important factor in the generation of pain in many neuropathic pain states. Although results to date have been mixed, there may be a greater role for new drugs which target peripheral alpha-2 adrenoceptors (agonists) or alpha-1 adrenoceptors (antagonists).

Key Words: Alpha-adrenoceptors; Complex regional pain syndrome; Neuropathic pain; Sympathetic nervous system
L'hypersensibilité aux adrénocepteurs alpha-1 dans trois états de douleur neuropathique : Le syndrome algodystrophique 1 , la douleur neuropathique périphérique diabétique et les états de douleur centrale après une lésion médullaire

La physiopathologie de la douleur associée au syndrome algodystrophique, à une lésion médullaire et à une neuropathie périphérique diabétique est inconnue. La douleur associée au syndrome algodystrophique est souvent attribuée à une activité anormale du système nerveux sympathique en raison d'une instabilité vasomotrice et d'une réponse souvent positive, quoique temporaire, à un blocage sympathique. Par contre, la douleur sous le niveau d'une lésion médullaire et d'une neuropathie périphérique diabétique est généralement perçue comme un phénomène de douleur par désafférentation. Chacun de ces états de douleur est relié à une fonction anormale du système nerveux sympathique et à un accroissement de l'activité des adrénocepteurs alpha-1 périphériques. Cette sensibilité accrue peut être la conséquence d'une hypersensibilité postsynaptique aux adrénocepteurs alpha-1 ou d'une dysfonction présynaptique des adrénocepteurs alpha-2 accompagnée d'une diminution du recaptage de la noradrénaline, d'un accroissement des concentrations de la noradrénaline dans la fente synaptique et d'une augmentation de la stimulation des adrénocepteurs alpha-1 autrement normaux. Des mécanismes plausibles ont été présentés, fondés sur des recherches auprès d'animaux selon lesquelles l'hypersensibilité aux adrénocepteurs alpha-1 peut entraîner une douleur chronique pseudo-neuropathique. Ce phénomène soulève la possibilité fascinante qu'une dysfonction du système nerveux sympathique, peut-être un facteur important de génération de douleur dans de nombreux états de douleur neuropathique. Bien que les résultats soient discutables jusqu’à présent, de nouveaux médicaments qui ciblent les adrénocepteurs alpha-2 (agonistes) périphériques ou les adrénocepteurs alpha-1 (antagonistes) pourraient jouer un rôle plus important.

\footnotetext{
A $\mathrm{t}$ first glance, the pain associated with complex regional pain syndrome type 1 (CRPS 1) (also known as reflex sympathetic dystrophy), spinal cord injury (SCI) and diabetic peripheral neuropathy would appear to have little in common. However, each of these conditions is characterized by pain, which is neuropathic in nature and whose pathophysiology is poorly understood. Moreover, each of these conditions is characterized by sympathetic nervous system (SNS) dysfunction and experimentally by peripheral alpha-1 adrenoceptor
}

hyperresponsiveness. We will demonstrate that these seemingly disparate pain conditions have a similar alpha-adrenoceptor response to noradrenaline, which may indicate a common underlying pathophysiology. The notion that alpha-adrenoceptors may be somehow linked to nociception is not new and has been referred to as sympathetically maintained pain (SMP). Ali et al (1) noted that, "several lines of clinical evidence support the hypothesis that SMP alpha-adrenoceptors develop in peripheral tissues (e.g. at the cutaneous terminal of nociceptors

${ }^{1}$ Physical Medicine and Rehabilitation; ${ }^{2}$ Internal Medicine; ${ }^{3}$ Lawson Research Institute; ${ }^{4}$ University of Western Ontario; ${ }^{5}$ Parkwood Hospital, St Joseph's Health Care London; ${ }^{6}$ London Health Sciences Centre, London, Ontario

Correspondence: Robert W Teasell, Parkwood Hospital, 801 Commissioners Road East, London, Ontario N6C 5J1. Telephone 519-685-4559,

fax 519-685-4023, e-mail robert.teasell@sjhc.london.on.ca 


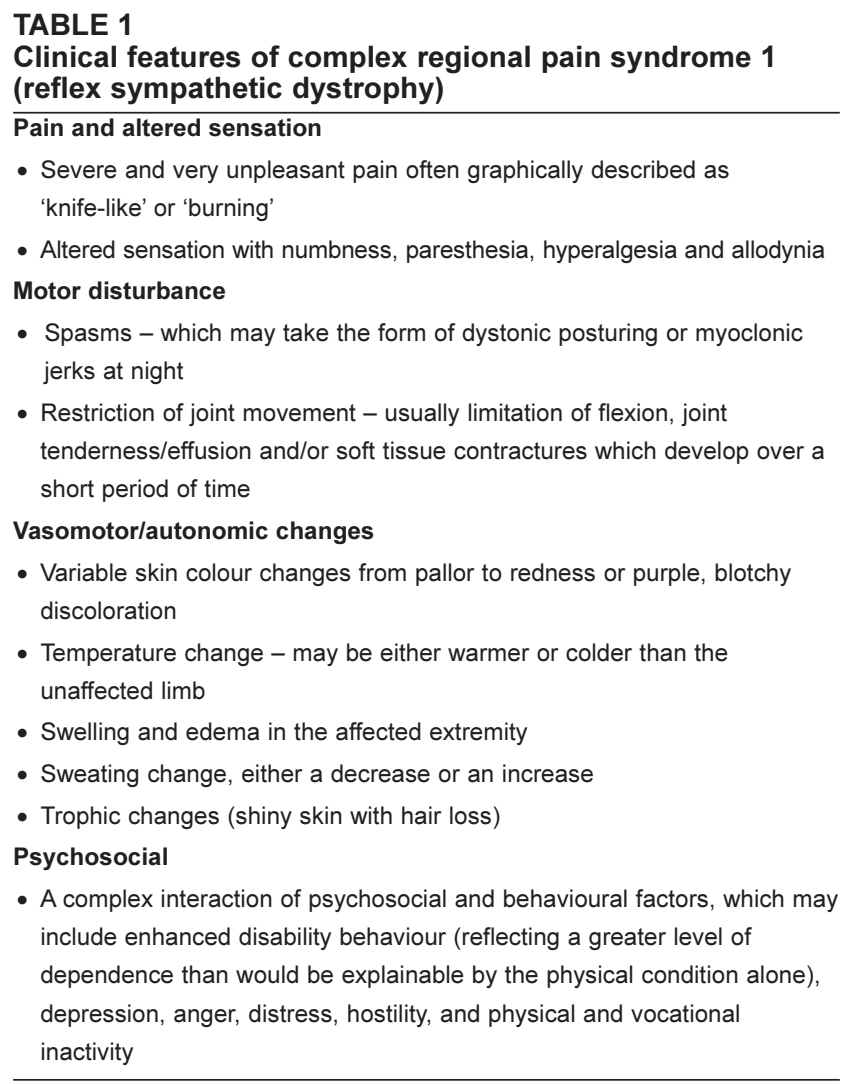

Data from reference 6

or at the site of nerve injury) such that the release of norepinephrine from the sympathetic terminals activates the nociceptors and leads to the sensation of pain (2)." For instance, in patients characterized as having SMP, intradermal injection of noradrenaline evoked pain whereas similar injections failed to do so in the unaffected arm or control subjects (1). Our research has revealed a remarkable linkage between the three neuropathic states, suggesting a potential common underlying pathophysiology.

\section{CRPS 1}

\section{CLINICAL CHARACTERISTICS OF NEUROPATHIC PAIN STATES}

CRPS 1 is a clinical disorder typically characterized by distal limb pain and edema, exquisite tenderness often in the form of allodynia (pain resulting from a non-noxious stimuli) or hyperalgesia (increased sensitivity to a noxious stimuli), protective immobility, in some cases trophic skin changes, and inevitably, vasomotor instability of the involved extremity (3-5). TurnerStokes (6) defined reflex sympathetic dystrophy (also known as CRPS 1) as "a complex and often poorly-understood condition characterized by: (a) pain and altered sensation; (b) motor disturbance and soft tissue change; (c) vasomotor and autonomic changes; and (d) psychosocial disturbance. Neurological symptoms typically do not conform to any particular pattern of nerve damage." The clinical features of CRPS 1 are listed in Table 1.

CRPS 1 commonly occurs following a peripheral trauma, for example, a wrist or ankle injury. The underlying pathophysiology of CRPS 1, in particular the pain, is not known.
Diabetic peripheral neuropathic pain

Diabetic patients frequently develop a peripheral neuropathy, which invariably involves the distal lower extremities. Involvement of both small and large nerve fibres is commonly seen in diabetics but small nerve fibres are frequently disproportionately involved, leading to autonomic dysfunction and dysesthetic pain. Dysesthesias, which are a frequent feature of diabetic polyneuropathy, have also long been regarded as a consequence of small fibre unmyelinated nociceptor dysfunction. Autonomic dysfunction, in particular abnormal SNS functioning, is a known consequence of small fibre neuropathy.

Diabetic neuropathic pain may be divided into two distinct categories based on the nature of the diabetic peripheral neuropathy $(7,8)$. The most common type of pain is a diffuse distal extremity dysesthetic pain with superficial or cutaneous pain characterized by burning and allodynia $(7,9,10)$. Less common is nerve trunk pain, which is generally attributed to a focal or mononeuropathy, in particular, the nerve roots. This pain is often described as a 'pins and needles' or an 'electric-like' pain $(9,10)$.

The signs and symptoms of diabetic peripheral neuropathy usually start in the toes and ascend proximally with time (11). Diabetic neuropathy patients often present with tingling, pricking and burning sensations in the feet (11), which can vary in intensity. When this pain is severe it may prevent or limit standing and walking (11). Allodynia may be present in the feet and patients may experience brief, sharp, lancinating pains. The pain may diminish as the numbness worsens. Stewart and Low (11) noted that, "it appears that, as the nerves become more damaged, their capacity to generate the abnormal action potentials, which are responsible for the positive symptoms is reduced..." However, increased pain and dysesthesias can paradoxically be present in a limb with reduced sensation.

Decreased sensation and diminished sympathetic activity in diabetic peripheral neuropathy is well understood as a failure of impulses or action potentials along diseased small peripheral nerve fibres (11). The cause of positive symptoms such as paresthesia and pain is not as clear, but numerous clinical observations and clinical findings have correlated with nerve biopsy samples, pointing to the damaged peripheral nervous system as the cause $(7,12-15)$. Stewart and Low (11) noted that the most commonly accepted theory with regards to diabetic neuropathic pain with reduced sensation, was that damaged small nociceptive fibres produced excessive nerve action potentials interpreted by the central nervous system as pain or dysesthesias. This concept, surrounding how damaged nerve fibres can produce both decreased sensation and pain, and paresthesia, often within the same patient, is a paradox which is not fully explained.

\section{SCI 'central pain'}

It is well recognized that patients with SCI often suffer from the effects of severe autonomic, in particular, SNS dysfunction below the level of their lesion. They also frequently suffer from 'central' or 'neurogenic' pain below or at the level of their SCI. This pain bears some remarkable similarities to the pain of CRPS 1 and diabetic peripheral neuropathy, yet central pain below the level of the lesion has defied a definite pathophysiological explanation. 'Central' dysesthesia or 'deafferentation' pain is a common type of pain seen following SCI and is generally characterized as a burning, aching and/or tingling 
sensation. It is most often perceived in a generalized manner below the level of the lesion $(16,17)$. Pain is generally more common following lumbar SCI or cauda equina lesions, although it may be found with SCI at thoracic and cervical levels (17). A number of factors may contribute to exacerbations of these 'central' pain states; these include visceral diseases or disturbances, movement, smoking or alcohol, emotional factors, fatigue and even weather changes (18-20). A full bladder in a quadriplegic may result in the paroxysmal hypertension of autonomic dysreflexia and an increased sense of burning below the level of the lesion (17). Occult injuries, such as a fracture, may produce an increase in this burning dysesthetic pain.

Patients with SCI also may experience a curious band of hyperalgesia at the marginal zone at the level of the lesion $(17,18,20-25)$. Even light touch or the pressure of clothing over this area may provoke marked discomfort (17). It may be accompanied by sweating or vasodilitation at or below the level of hyperalgesia. Although multiple hypotheses for this border zone hyperalgesia have been proposed, the neurological mechanism responsible for this phenomenon remains unexplained. It is most commonly attributed to injured nerve roots or a radicular type pain, although typically it occurs in a ring or girdle-like manner, which is not characteristic of a radicular pain state. Characteristically, hyperalgesia or allodynia is also present and thus it bears remarkable clinical similarities to the pain of CRPS 1.

\section{SNS DYSFUNCTION}

\section{Differences between acute and chronic CRPS 1}

SMP: CRPS 1 has long been regarded as a consequence of an abnormal SNS, based largely on vasomotor instability and a frequent positive response to sympathetic blockade. However, the specific role of the SNS in CRPS 1 remains unclear. Terms such as SMP have often been used to describe those cases thought to be responsive to sympathetic blockade (26). Campbell et al (2) went so far as to diagnose CRPS 1 when the pain was eliminated by blockade of sympathetic efferent innervation of the pain area, eg, sympathetic dependent and independent pain $(2,26)$. Janig (27) noted that the clinical phenomenology of CRPS 1 and the use of sympathetic blocks to treat the syndrome complex favours the hypothesis that the efferent SNS is involved in maintenance of CRPS 1 and is coupled in some abnormal way to afferent input from the periphery (28). Arnold et al (29) have provided research evidence of hyperresponsiveness of peripheral alpha- 1 adrenoceptors in the affected limb in CRPS 1.

Acute CRPS 1: Several studies and the clinical picture support the concept, at least in the initial phase, that the SNS in CRPS 1 is abnormal (29-33). A unilateral vasomotor disturbance is a typical feature of CRPS. Vasoconstrictor tone has been assumed to be reduced in the affected limb of patients with CRPS 1, primarily based on the clinical picture of swelling, warmth and rubor $(34,35)$. In acute CRPS, skin temperature is increased; this is thought to be due to inhibition of sympathetic vasoconstrictor activity due to impairment of sympathetic vasoconstrictor reflexes (36). There is also a central component because sympathetic vasoconstrictor reflexes induced by central activity (mental distress) are reduced in the affected limb (36). Bej and Schwartzman (37) and Rosen et al $(38,39)$ demonstrated limited or absent autonomic response to autonomic nervous system stimuli in affected limbs of patients with CRPS 1 . Whole body cooling induces less vasoconstriction on the affected side (36). Kozin et al (4) described 15 CRPS 1 patients with increased blood flow and only three with decreased blood flow. Drummond et al (30), confirmed by Harden (1994), reported that plasma noradrenaline and its intracellular metabolite 3,4-dihydroxyphenylethyleneglycol was lower in the affected CRPS 1 limb when compared with the nonaffected limb.

Chronic CRPS 1: The clinical picture of chronic CRPS 1 includes decreased skin temperature with redevelopment of vasoconstrictor abilities (36). Therefore, in cases where CRPS 1 was diagnosed based on clinical criteria, there is suggestive evidence that the SNS in the affected limb is abnormal. It is not known whether this is due to peripheral adrenergic denervation supersensitivity or reconstitution of central sympathetic efferent control (36) - increased activity of the SNS has previously been thought to be the underlying pathophysiological mechanisms in chronic CRPS 1. Vasomotor changes, measured by skin temperature difference, change over time, with a warmer affected extremity in the acute phase and a cold limb in the chronic phase. Regional sympathetic blocks and even sympathectomy are frequently employed in the treatment of chronic CRPS 1, although, Ochoa and Verdugo (40) have questioned whether SNS blocks are superior to a similarly administered placebo in terms of pain relief $(41,42)$.

Early and late changes in diabetic peripheral neuropathy Diminished peripheral sympathetic tone or sympathetic denervation occurs in diabetics, leading to increased blood flow, which is detectable even before there is clinical evidence of neuropathy (43). Venous occlusion plethysmograph, which measures total arterial inflow, has demonstrated increased peripheral blood flow (44) while spontaneous variations in resting blood flow, which are secondary to sympathetic activity, are considerably reduced in the diabetic neuropathic foot. An increase in blood flow reportedly associated with arteriovenous shunting in the neuropathic limb has been reported over the dorsum of the foot and lower part of the calf (45). In normal subjects, upon standing, there is a fall in blood flow in the peripheral limb. In diabetic neuropathy there is less of a fall in blood flow compatible with loss of sympathetic vascular tone (43). Tack et al (46) demonstrated that regionally selective sympathetic denervation was present in the painful feet of patients with diabetic neuropathy.

Sweating and vasomotor abnormalities occur most often in the distal lower extremities and are mediated primarily by small unmyelinated fibres. Though clinical symptoms stemming from involvement of autonomic fibres are uncommon, some patients note the development of anhidrosis of their feet or vasomotor changes manifested by discolouration or temperature changes (11). Symptoms of more widespread autonomic involvement are usually a later occurrence seen in advanced diabetes.

\section{Resting and stress differences in SCI}

A high complete SCI results in reduced SNS efferent outflow below the level of the SCI. Immediately after the SCI, plasma adrenaline and noradrenaline, and their urinary metabolites are normally in the low normal range (47) and tend to remain low as long as there is no stimulation below the level of SCI, 

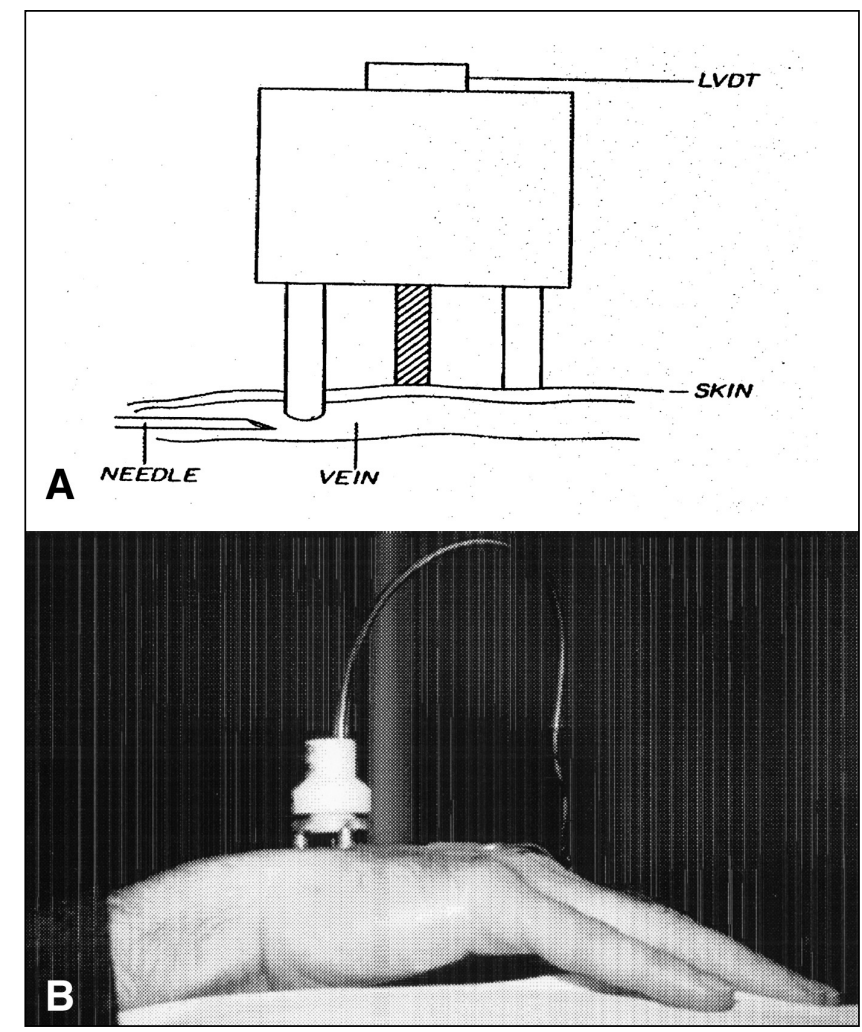

Figures $1 \mathrm{~A}$ and $\mathrm{B})$ The linear variable differential transformer (LVDT) is placed over a large hand vein in patients with complex regional pain syndrome type 1 just distal to the end of a 25 gauge butterfly needle placed in the vein. The LVDT is able to measure changes in the diameter of the vein at different concentrations of noradrenaline infused through the butterfly needle. This provides an indirect measurement of alpha-adrenoresponsiveness in that vein to noradrenaline

such as a full bladder (47-53). Mathias et al (54) reported that resting catecholamine levels in individuals with cervical SCIs were below normal when compared with normal controls and paraplegic subjects.

Sympathetic efferent outflow is therefore diminished with a decrease in plasma noradrenaline at rest $(5,55)$. Clinically, these individuals suffer from problems with thermoregulation as well as resting and orthostatic hypotension as a result of SNS hypoactivity $(51,56-59)$. However, serum noradrenaline levels may rise significantly during catheterization with corresponding increases in blood pressure (60). It has also been shown that quadriplegics with cervical spinal cord transection have an enhanced pressor response to noradrenaline (61), while identical infusions of noradrenaline in quadriplegics and controls without cervical spinal cord transection result in markedly different pressor responses $(61,62)$.

\section{ALPHA-ADRENOCEPTOR HYPERRESPONSIVENESS}

Evidence for alpha-1 hyperresponsiveness of peripheral alpha-adrenoceptors in CRPS 1

The fact that the SNS appears to be abnormal has led to the concept that alpha-adrenoceptor function must be altered. Some have gone as far as implicating alpha-adrenoceptors in the generation of pain seen in CRPS 1 (2). It is known that

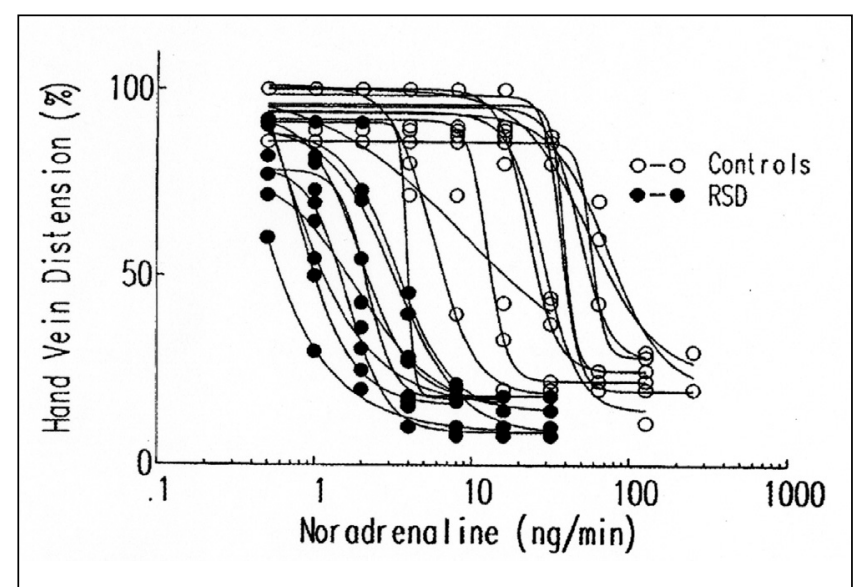

Figure 2) Individual dose-reponse curves were constructed and the dose of noradrenaline required to constrict the vein to $50 \%$ of baseline value was calculated. This value, known as the ED5O, becomes a measurement of the responsiveness of alpha-adrenoceptors in the venous walls to noradrenaline. Higher values means that it took a greater concentration of noradrenaline to constrict the vein to $50 \%$ of its baseline value, ie it was less responsive. RSD Reflex sympathetic dystrophy (also known as complex regional pain syndrome type 1). Printed with permission from the Annals of Internal Medicine (29)

alpha-adrenoceptors are located in blood vessel walls and generally mediate vasoconstriction induced by noradrenaline (2). This is perhaps their best known role and the function most accessible to research studies. Alpha-adrenoceptors can be subdivided into two types. Alpha-1 adrenoceptors are postsynaptic and mediate vasoconstriction when stimulated by noradrenaline. Alpha-2 adrenoceptors are post- and presynaptic, and the latter when stimulated, results in increased reuptake of noradrenaline from the synaptic cleft. Postsynaptic alpha-adrenoceptor hyperresponsiveness potentially could result from hypersensitivity of postsynaptic alpha-1 or alpha-2 adrenoceptors or decreased presynaptic alpha-2 adrenoceptor function, the latter resulting in increased concentrations of noradrenaline at the synaptic junction and increased stimulation of the alpha-1 adrenoceptor.

There is a substantial body of literature suggesting alphaadrenoceptor function abnormally in CRPS 1. Our group (29) have demonstrated marked hyperresponsiveness of venous alpha-adrenoceptors to locally infused noradrenaline in hands affected by CRPS 1 when compared with the opposite (unaffected) hand and normal controls. In this study, progressively increasing concentrations of noradrenaline were infused into the dorsal hand veins of CRPS 1 patients and control subjects distal to a device designed to measure vein diameter (Figures $1 \mathrm{~A}, \mathrm{~B}$ ). Individual dose-reponse curves were constructed (Figure 2) and the dose of noradrenaline required to constrict the vein to $50 \%$ of baseline value was calculated. This value, known as ED5O, becomes a measurement of the responsiveness of alpha-adrenoceptors in the venous walls to noradrenaline. The noradrenaline ED5O was $27.9 \mathrm{ng} / \mathrm{min}$ in the hands of normal controls while only $1.5 \mathrm{ng} / \mathrm{min}$ in the hand affected with reflex sympathetic dystrophy (Table 2, Figure 3). Hence, the CRPS 1 hand veins were markedly more sensitive to noradrenaline than normal controls and contracted to one half the baseline size at a much lower concentration. It is probable that such 
TABLE 2

The noradrenaline ED50* in complex regional pain syndrome type 1 (CRPS 1) and quadriplegia

\begin{tabular}{llc}
\hline & N & ED50 Noradrenaline \\
\hline CRPS 1 affected hand & 11 & $1.5 \mathrm{ng} / \mathrm{min}$ \\
Normal controls (hand) & 11 & $27.9 \mathrm{ng} / \mathrm{min}$ \\
Quadriplegic foot & 6 & $1.6 \mathrm{ng} / \mathrm{min}$ \\
Normal controls (foot) & 6 & $10.9 \mathrm{ng} / \mathrm{min}$ \\
\hline
\end{tabular}

*The ED5O is the effective dose of noradrenaline required to cause $50 \%$ constriction of the vein diameter at $45 \mathrm{mmHg}$. Determined from semi-logarithmic dose-response curves constructed using, nonlinear curve-fitting program (Graph-Pad In Plot, version 4.0, Graph Pad Software, USA)

hyperresponsiveness of alpha-adrenoceptors would not be confined to the vascular smooth muscle wall; similar phenomena have been hypothesized to account for the hyperalgesia and allodynia seen in CRPS 1 (2,30,63). Drummond et al (30) suggested that the hyperhidrosis, vasomotor instability, spontaneous pain and allodynia occurred as a result of the consequent supersensitivity to sympathetic neurotransmitters. The number of alpha- 1 adrenoceptors was increased in the hyperalgesic skin of patients with CRPS 1 (64). Kurvers et al (65) found that denervation-induced supersensitivity to catecholamines occurred in sciatic nerve ligation in rats, an experimental model of neuropathic pain.

\section{Alpha-adrenoceptor responsiveness in a broad range of diabetic patients}

Stewart and Low (11) noted that diabetic patients often complain that their feet are cold. Blood vessels may narrow due to denervation hypersensitivity triggered by circulating catecholamines (11). Another explanation may be arterial disease, which is commonly associated with diabetes mellitus (11). A final possible explanation is that abnormal sensory afferent signals may be misinterpreted by patients as a sensation of coldness (11).

Several studies $(66,67)$ have used this technique in insulindependent diabetes. Bodmer et al (66) compared the dorsal hand veins of 25 insulin-dependent diabetes mellitus (IDDM) patients (15 with microalbuminuria, 10 without; no symptoms or signs of autonomic neuropathy) with 10 normal controls. The ED5O for noradrenaline was significantly lower in the dorsal hand veins of microalbuminuric IDDM patients compared with normoalbuminuric IDDM patients and controls (Figure 4). Interestingly, they did not demonstrate a difference in the response of blood vessels (as measured by the ED50) to phenylephrine. There was a positive linear correlation between the ED50 to noradrenaline and nerve conduction velocity suggesting an association between peripheral nerve dysfunction and vascular hyperresponsiveness. Bodmer et al (66) found that administration of an alpha-1 adrenoceptor antagonist, doxazosin, in IDDM with microalbuminuria patients, significantly reduced this exaggerated vascular reactivity to noradrenaline. Eichler et al (67) compared 20 IDDM patients with autonomic neuropathy (10 symptomatic, 10 asymptomatic) with 14 normal controls. The ED50 to noradrenaline was lower in symptomatic diabetics compared with asymptomatic diabetics and normal controls. There was no difference in the ED50 response to phenylephrine in diabetics (either microalbuminuria or normal albuminuria) when compared with phenylephrine in the controls.

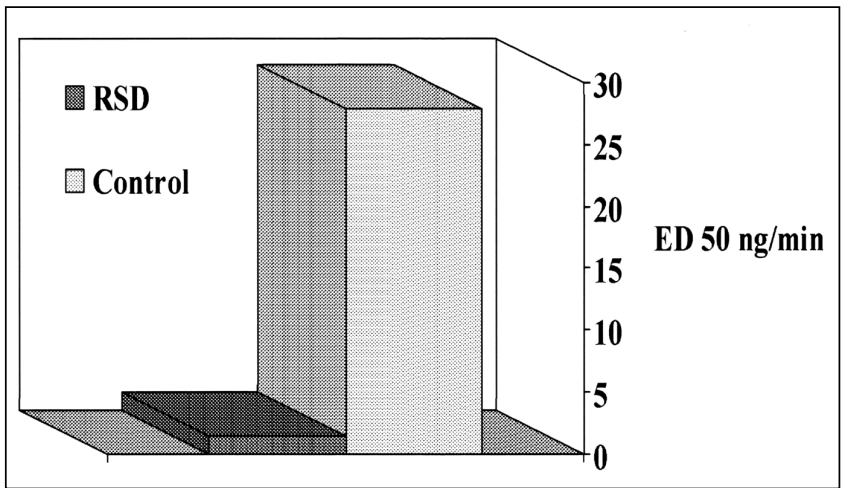

Figure 3) In the hand veins of normal controls the noradrenaline ED5O was $27.9 \mathrm{ng} / \mathrm{min}$ while in the hand veins affected with reflex sympathetic dystrophy (RSD) (also known as complex regional pain syndrome type 1 [CRSPS 1]) it was a mere $1.5 \mathrm{ng} / \mathrm{min}$. Hence, the CRPS 1 hand veins were markedly more sensitive to noradrenaline than normal controls, contracting to one half the baseline size at a much lower concentration

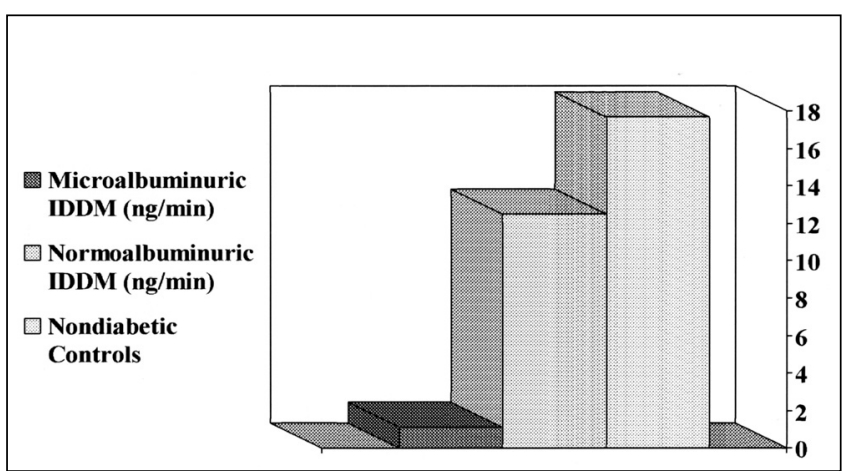

Figure 4) Comparison of ED50 in hand veins of diabetics ( \pm microalbuminuria) and nondiabetics (66). IDDM insulin-dependent diabetes mellitus Bodmer et al (66) compared 25 insulin-dependent diabetes mellitus (IDDM) patients (15 with microalbuminuria, 10 without; no symptoms or signs of autonomic neuropathy) with 10 normal controls. The ED5O for noradrenaline was significantly lower in microalbuminuric IDDM patients compared with normoalbuminuric IDDM patients and controls. This indicates that alpha-adrenoceptor hyperresponsiveness is most significant in more severe diabetic neuropathic patients

Phenylephrine directly stimulates alpha-1 and not alpha-2 adrenoceptors but in diabetic peripheral neuropathy patients there was no exaggerated vasoconstrictor effect with phenylephrine indicating the vascular response was not a consequence of alpha-1 adrenoceptor supersensitivity. In contrast, locally infused noradrenaline led to a hyperresponsive vasoconstriction. This could result from diminished presynaptic alpha-2 adrenoceptor activity with increased noradrenaline at the synaptic junction leading to an increased alpha-1 adrenoceptor response. This hypothesis was supported indirectly by the higher circulating noradrenaline levels in the patients with a clinical diabetic peripheral neuropathy (68), which provides some evidence that transdermal clonidine (an alpha-2 agonist) is more effective than placebo in reducing the pain of peripheral diabetic neuropathies (69), although phentolamine (an alpha-1 antagonist) did not similarly relieve the pain (70). 


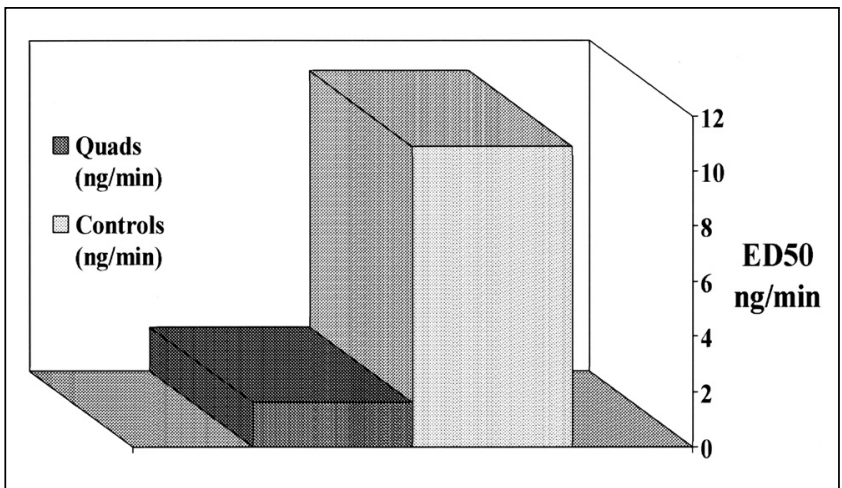

Figure 5) Alpha-adrenoceptor responsiveness in foot veins of quadriplegics. The foot veins of the quadriplegics demonstrated a markedly exaggerated vasconstrictor response to noradrenaline, with an ED5O of $1.6 \mathrm{ng} / \mathrm{mn}$ versus $10.9 \mathrm{ng} / \mathrm{min}$ in normal controls, demonstrating alpha-adrenoceptor hyperresponsiveness was present below the level of spinal cord injury

One hypothesis which could account for these findings is a dysfunctional SNS due to small fibre damage with a diminished ability of alpha- 2 receptors to presynaptically reuptake noradrenaline resulting in excessive stimulation of the alpha-1 adrenoceptor, which in turn contributes to local vasoconstriction and potentially pain. If it is mediated ultimately through alpha-1 adrenoceptors and results show phentolamine was not effective, this will suggest a low basal release of noradrenaline from nerves. Obviously more research is needed.

\section{Alpha-adrenoreceptor hyperresponsiveness in SCI}

In SCI, the vascular system appears to become overresponsive to the effects of noradrenaline. It has been speculated that this is due in part to alpha-adrenoceptor hyperresponsiveness on the arterial side. Such hyperresponsiveness has been shown to be present in quadriplegics on the venous side of the circulation $(59,71)$. Release of noradrenaline from postganglionic fibres in reaction to a peripheral or visceral stimulus is known to result in marked vasoconstriction of blood vessels below the spinal cord lesion $(49,72)$. If the lesion is above thoracic level six, sufficient vasoconstriction occurs to precipitate autonomic dysreflexia, which is often characterized by severe paroxysmal hypertension $(49,73)$. Autonomic dysreflexia occurs in up to $90 \%$ of quadriplegics and high paraplegics (72-74). During a bout of autonomic dysreflexia there are signs of sympathetic hyperactivity below the level of the lesion with hypertension (often severe), pallor, piloerection and sudomotor sweating (72). Autonomic dysreflexia is triggered by a stimulus (usually bladder or visceral) below the level of the lesion which stimulates an SNS response in the absence of supraspinal inhibitory influences (56). Thus, a paradoxical situation exists with SCI patients, whereby at rest the SNS appears to be underactive but with appropriate stimulation the SNS response is that of marked hyperactivity not dampened by supraspinal control.

A study looking at the responsiveness of dorsal foot veins to locally infused noradrenaline in quadriplegics by our group (71) found that it occurred in a manner very similar to that found in our studies of dorsal hand veins in patients with CRPS 1 (29) and by Bodmer et al's study (66) in insulin dependent diabetics with microalbuminuria. The foot veins of the quadriplegics demonstrated a markedly exaggerated vasconstrictor response to noradrenaline, with a ED5O of
$1.6 \mathrm{ng} / \mathrm{min}$ versus $10.9 \mathrm{ng} / \mathrm{min}$ in normal controls, suggesting alpha-adrenoceptor hyperresponsiveness was present below the level of SCI as well (Figure 5).

\section{Alpha-adrenoceptors and nociception}

If alpha-adrenoceptors are to be implicated in CRPS 1, they must be somehow linked to the development of nociception. Hyperalgesia associated with nerve injury has been associated with the production and release of mediators that act on peripheral nociceptors (75). Some of these mediators, such as prostaglandin E2 (PGE2) and prostacyclin (PG12) appear to produce hyperalgesia by a direct action on primary nociceptors (76-78). In contrast, experimentally, noradrenaline produces nociceptor sensitization indirectly by stimulating other neuronal cells (75). Based on observations that noradrenaline hyperalgesia can be blocked both by sympathectomy (79) and by cycloxygenase inhibitors (79) and that sympathetic postganglionic neurons (SPGN) produce PGE2 and PGI2 (80), Levine et al (79) have suggested that the hyperalgesia induced by noradrenaline is mediated by prostaglandins produced by SPGN terminals. More specifically, in experimental rats noradrenaline hyperalgesia has been shown to be mediated by alpha-adrenoceptors on SPGN terminals after injury (79). Taiwo and Levine (81) have suggested that this noradrenalineinduced hyperalgesia in injured skin is mediated by PGI2. This provides a link by which alpha-1 adrenoceptors, once excessively stimulated, may lead to the release of prostaglandins and subsequent nociception.

More recently, Huygen et al (82) have noted that, "Only limited data are available for inflammatory mediators in complex regional pain syndrome type 1 measured in the hand, wrist, foot or ankle exhibiting signs of post traumatic dystrophy. There is, however, enough direct and indirect evidence to state that neurogenic inflammation underlies both early and chronic symptoms observed in complex regional pain syndrome type 1." Further discussion of this issue is beyond the scope of this article.

\section{THERAPEUTIC APPROACHES}

\section{Therapeutic approaches to CRPS 1}

As mentioned previously, regional sympathetic blocks and sympathectomy are frequently employed in the treatment of CRPS 1. However, results are often disappointing and reported benefits inadequately controlled. Further evidence arises from a large body of predominately uncontrolled studies of medications that target alpha-adrenoceptors. Oral phenoxybenzamine blockade (83), phentolamine infusion $(84,85)$, guanethidine regional blocks $(32,58)$ and prazosin $(86)$ have been reported to, at the least, temporarily alleviate the pain of CRPS 1, albeit inconsistently. Guanethidine works by depleting noradrenaline from sympathetic terminals while phentolamine, phenoxybenzamine and prazosin are alpha-1 adrenoceptor blockers. Systemic treatment of CRPS 1 with phentolamine, a short-acting competitive alpha-1 adrenergic antagonist, has been reported to effectively reduce pain to the same degree as a chemical sympathectomy $(2,84)$ or a local anaesthetic block of sympathetic impulse activity (24); however, one study found no difference in outcome when phentolamine blockade was compared with placebo controls $(41,42)$.

In a related line of evidence, topical clonidine, an alpha-2 adrenoceptor agonist, relieved the pain of CRPS 1 when applied locally to the region of hyperalgesia in case studies 
(87). Clonidine did not lead to anaesthesia in these patients but rather normalized pain thresholds. When this area, rendered free of hyperalgesia by clonidine, was injected with noradrenaline or phenylephrine, both alpha-1 adrenoceptor agonists, hyperalgesia recurred (87). The fact that clonidine was able to relieve the hyperalgesic pain when applied locally suggests that the problem was due to a disorder of the alpha-2 adrenoceptor with decreased reuptake of noradrenaline presynaptically. This hyperresponsiveness may be the consequence of increased noradrenaline at the synaptic junction due to decreased presynaptic reuptake.

\section{DISCUSSION}

As mentioned earlier, there are some intriguing clinical similarities in the pain associated with CRPS 1, painful diabetic neuropathy and SCI pain. All these are associated in clinical experiments with vascular or venous alpha-adrenoceptor hyperresponsiveness to noradrenaline in the affected limbs. Therefore, the three conditions associated with chronic pain have clinical similarities in their presentations despite quite disparate etiologies. They are also each associated with alphaadrenoceptor hyperresponsiveness which in the past has been postulated to be a factor only in the pain of CRPS 1. Finally, animal experiments have suggested a plausible linkage between alpha-adrenoceptors and nociceptive mediators.

All of these conditions are characterized by a burning pain often associated with allodynia. However, the 'central' neuropathic pain seen after SCI may have the severity of the pain blunted by diminished sensation below the level of the spinal cord lesion. In contrast, the border zone or segmental dysesthetic pain sometimes seen in SCI patients does bear remarkable similarities to the pain of CRPS 1 (Table 3). We postulate that, where the upper zone of alpha adrenoreceptors abnormalities occurs concurrently with the lower limits of normal or near-normal sensation, it would be expected to result in severe pain and allodynia, which does in fact occur at the border zone margin of SCI. Although in the past such pain has been attributed to a radicular etiology, unlike radicular pain, it occurs in a band or girdle at the level of SCI both bilaterally and antero-posteriorly. Diabetic neuropathic pain has been loosely associated with SNS dysfunction and the pain has characteristics often similar to that previously described.

We have offered evidence for a hypothesis which postulates that CRPS 1, diabetic peripheral neuropathy and SCI have SNS abnormalities characterized by abnormal peripheral SNS' and alpha-adrenoceptor hyperresponsiveness. It would appear that, at least in diabetic peripheral neuropathy, this hyperresponsiveness of alpha-adrenoceptors is due to alpha-2 adrenoceptor dysfunction and a decrease in presynaptic uptake of noradrenaline. This in turn would be expected to produce higher concentrations of noradrenaline in the synaptic cleft with subsequent overstimulation of the receptor. Stimulating the alpha-1 adrenoceptor with an alpha-adrenergic agonist other than noradrenaline, ie, phenylephrine, does not lead to a similar response, suggesting that alpha-1 adrenoceptor function is otherwise normal.

This hypothesis is appealing because it offers a unifying hypothesis for seemingly disparate neuropathic pain states. Although these conditions have clinical similarities, and now experimentally demonstrable SNS abnormalities, their etiologies are remarkably different. The actual pathophysiology of the pain in each of these conditions is poorly understood;

\begin{tabular}{|c|c|}
\hline CRPS 1 & $\mathrm{SCl}$ central pain \\
\hline Develops weeks to months post injury & $\begin{array}{l}\text { Develops weeks to months } \\
\text { postinjury }\end{array}$ \\
\hline Variable clinical picture & Variable clinical picture \\
\hline Frequent spontaneous pain & Frequent spontaneous pain \\
\hline Burning, aching, dysesthetic pain & Burning, aching dysesthetic pain \\
\hline Allodynia and/or hyperalgesia & $\begin{array}{l}\text { Allodynia and/or hyperalgesia; may } \\
\text { be muted by sensory loss }\end{array}$ \\
\hline Aggravated by activity, stress & $\begin{array}{l}\text { Aggravated by activity, autonomic } \\
\text { stimulation }\end{array}$ \\
\hline Relieved by rest & Relieved by rest \\
\hline Swelling, vasomotor instability & Swelling, vasomotor instability \\
\hline $\begin{array}{l}\text { Poor response to medications } \\
\text { (with possible exception of } \\
\text { alpha-blockers and psychotropics) }\end{array}$ & $\begin{array}{l}\text { Poor response to medications } \\
\text { (with possible exception of } \\
\text { alpha-blockers and psychotropics) }\end{array}$ \\
\hline $\begin{array}{l}\text { Diminished sympathetic outflow } \\
\text { to affected limb }\end{array}$ & $\begin{array}{l}\text { Sympathetic failure below the level } \\
\text { of } \mathrm{SCl}\end{array}$ \\
\hline $\begin{array}{l}\text { Hypersensitization of alpha } \\
\text { adrenoceptors in the affected limb }\end{array}$ & $\begin{array}{l}\text { Hypersensitization of alpha } \\
\text { adrenoceptors below level of SCI }\end{array}$ \\
\hline Central modulation & Central origin \\
\hline
\end{tabular}

alternative explanations are poorly substantiated. The major limitation of our hypothesis is the poorly defined linkage between the SNS and nociception. If SNS dysfunction leads to neuropathic pain states, one would expect that treatments aimed at altering SNS function would result in at least a temporary lessening of the pain. However, studies of treatment of these pain states using drugs that target the SNS have had mixed results. Part of the difficulty has been not knowing if the problem is a consequence of SNS hyperactivity, alpha-1 adrenoceptor hypersensitivity, alpha-2 adrenoceptor dysfunction, or some other undefined mechanism linked to our experimental findings.

If alpha-adrenoceptor hyperresponsiveness contributes to neuropathic pain and is a consequence of alpha- 2 receptor dysfunction with diminished presynaptic reuptake of noradrenaline, then treatment aimed at improving presynaptic reuptake should reduce the pain. The most commonly used alpha-2 agonist is clonidine, although when taken orally it acts more centrally, but when used locally as a cream it has been used to treat both CRPS 1 and diabetic neuropathic pain. If this hypothesis is in fact true, and SNS abnormalities manifested as alpha-1 adrenoceptor hyperresponsiveness prove to be a contributor to 'neuropathic' pain, then more effective treatment may be developed to manage the pain in the future.

Future research needs to focus on better defining the role of alpha-1 adrenoceptors, and looking at vascular reactivity to phenylephrine versus noradrenaline in CRPS 1 and SCI patients. Relating these changes to pain, based on clinical findings and experimental findings of alpha-adrenoceptor changes, is important. Finally, the goal is to develop and test treatments designed to effectively treat the pain.

ACKNOWLEDGEMENT: We would like to thank Ms Sanjit Bhogal for her assistance in preparing this manuscript. 


\section{REFERENCES}

1. Ali Z, Raja SN, Wesselmann U, Fuchs PN, Meyer RA, Campbell JN. Intradermal injection of norepinephrine evokes pain in patients with sympathetically maintained pain. Pain 2000;88:161-8.

2. Campbell JN, Meyer RA, Raja SN. Is nociceptor activation by alpha-1 adrenoceptors the culprit in sympathetically maintained pain (SMP)? Am Pain Soc J 1992;1:3-11.

3. Kozin F, Genant HK, Bekerman C, McCarty DK. The reflex sympathetic dystrophy syndrome. II. Roentgenographic and scintigraphic evidence of bilaterality and of periarticular accentuation. Am J Med 1976;60:332-8.

4. Kozin F, McCarty DJ, Sims JE, Genant HK. The reflex sympathetic dystrophy syndrome I. Clinical and histologic studies: Evidence of bilaterality, response to corticosteroids and articular involvement. Am J Med 1976;60:321-31.

5. Kozin F, Ryan LM, Carerra GF, Soin JS, Wortmann RL. The reflex sympathetic dystrophy syndrome (RSDS) III. Scintigraphic studies, further evidence for the therapeutic efficacy of systemic corticosteriods and proposed diagnostic criteria. Am J Med 1981;70:23-30.

6. Turner-Stokes L. Reflex sympathetic dystrophy - a complex regional pain syndrome. Disabil Rehabil 2002;24:939-47.

7. Ashbury AK, Fields HL. Pain due to peripheral nerve damage: A hypothesis. Neurology 1984;34:1587-90.

8. Boulton A. What causes neuropathic pain? J Diabetic Complications 1992;6:58-63.

9. Pfeifer MA, Ross DR, Schrage JP, et al. A highly successful and novel model for treatment of chronic painful diabetic peripheral neuropathy. Diabetes Care 1993;16:1103-15.

10. Fields HL. Painful dysfunction of the nervous system. In: Fields HL, ed. Pain. New York: McGraw-Hill Information Services Company, 1987:133-69.

11. Stewart JD, Low PA. Small-fiber neuropathy. In: Low PA, ed. Clinical Autonomic Disorders. Boston: Little Brown and Company, 1993:653-66.

12. Brown MJ, Ashbury AK. Diabetic neuropathy. Ann Neurol 1984;15:2-12.

13. Dyck PJ, Lambert EH, O'Brien PC. Pain in peripheral neuropathy related to rate and kind of fiber degeneration. Neurology 1976;26:466-71.

14. Said G, Slama G, Selva J. Progressive centripetal degeneration of axons in small fibre diabetic polyneuropathy: A clinical and pathological study. Brain 1983;106:791-807.

15. Sivak M, Ochoa J. Positive manifestation of nerve fiber dysfunction: Clinical, electophysiologic and pathologic correlates. In: Brown WF, Bolton CF, eds. Clinical Electromyography. Boston: Butterworths, 1987:3-30.

16. Britell CW, Mariano AJ. Chronic pain in spinal cord injury. Physical Medicine and Rehabilitation: State of the Art Reviews 1991;5:71-82.

17. Tunks E. Pain in spinal cord injuries patients. In: Bloch RF, Busbaum, eds. Management of Spinal Cord Injuries. Baltimore: Williams \& Wilkins, 1986:180-211.

18. Botterell EH, Callaghan JC, Jousee AT. Pain in paraplegia: Clinical management and surgical treatment. Proc R Soc Med 1954;47:281-8.

19. Davis L, Martin J. Studies upon spinal cord injuries: The nature and treatment of pain. J Neurosurg 1947;4:483-91.

20. Davis R. Pain and suffering following spinal cord injury. Clin Orthop 1975;112:76-80.

21. Heliporn A. Two therapeutic experiments on stubborn pain in spinal cord lesions: Coupling melitracen-flupenthixol and the transcutaneous electrical stimulation. Paraplegia 1977;15:353-67.

22. Kaplan LI, Grynbaum BB, Lloyd KE, Rusk HA. Pain and spasticity in patients with spinal cord dysfunction: Results of a follow-up study. JAMA 1962;182:918-25.

23. Maury M. About pain and its treatments in paraplegics. Paraplegia 1977;15:349-52.

24. Melzack R, Loeser JD. Phantom body pain in paraplegics: Evidence for a central "pattern generating mechanism" for pain. Pain 1978;4:195-210.

25. Michaelis LS. The problem of pain in paraplegia and tetraplegia. Bull N Y Acad Med 1970;46:88-96.

26. Roberts WJ. A hypothesis on the physiological basis for causalgia and related pains. Pain 1986;24:297-311.
27. Janig W. The sympathetic nervous system in pain: Physiology and pathophysiology. In: Stanton-Hicks M, ed. Pain and the Sympathetic Nervous System. Boston and London: Kluwer Academic, 1990:17-89.

28. Janig W. Can reflex sympathetic dystophy be reduced to an alphaadrenoceptor disease. Am Pain Soc J 1992;1:16-22.

29. Arnold JMO, Teasell RW, Macleod AP, Brown JE, Carruthers SG. Increased venous alpha-adrenoceptor responsiveness in patients with reflex sympathetic dystrophy. Ann Intern Med 1993;118:619-21.

30. Drummond PD, Finch PM, Smythe GA. Reflex sympathetic dystrophy: The significance of differing plasma catecholamine concentration in affected and unaffected limbs. Brain 1991;114:2025-36.

31. Hodges DL, McGuire TJ. Burning and pain after injury. Is it causalgia or reflex sympathetic dystrophy? Postgrad Med 1988;83:185-92.

32. Jaeger SH, Singer DI, Whitenack SH, Mandel S. Nerve injury complications. Management of neurogenic pain syndromes. Hand Clin 1986;2:217-34.

33. Steinbrocker O. The shoulder-hand syndrome. Am J Med 1947;3:402-7.

34. Christensen K, Henrikson O. The reflex sympathetic dystrophy syndrome: An experimental study of sympathetic reflex control of subcutaneous blood flow in hand. Scand J Rheumatol 1983;12:263-7.

35. Meyer RA, Raja SN, Treede RD, Davis KD, Campbell JN. Pleural mechanisms of sympathetically maintained pain In: Janig W, Schmidt RF, eds. Reflex Sympathetic Dystrophy: Pathophysiological Mechanisms of Reflex Sympathetic Dystrophy. Wenheim: VCH Verlagsgesellschaft, 1992.

36. Wasner G, Drummond P, Birklein F, Baron R. The role of the sympathetic nervous system in autonomic disturbances and "sympathetically maintained pain" in CRPS. In: Harden RN, Baron R, Janig W, eds. Complex Regional Pain Syndrome, Progress in Pain Research and Management. Seattle: IASP Press, 2001:89-119.

37. Bej MD, Schwartzman RJ. Abnormalities of cutaneous blood flow regulation in patients with reflex sympathetic dystrophy as measured by laser Doppler fluxmetry. Arch Neurol 1991;48:912-5.

38. Rosen L, Ostergren J, Roald OK, Stranden E, Fagrell B. Bilateral involvement and the effect of sympathetic blockade on skin micro circulation in the sympathetic dystrophies. Microvasc Res 1989;37:289-97.

39. Rosen L, Ostergren J, Fagrell B, Stranden E. Skin microvascular and circulation in the sympathetic dystrophies evaluated by vidiophotometric capillaroscopy and laser Doppler fluxmety. Eur J Clin Invest 1988;18:305-8.

40. Ochoa JL, Verdugo RL. The mythology of reflex sympathetic dystrophy and sympathetically maintained pains. Phys Med Rehabil Clin N Am 1993:4:151-63.

41. Verdugo R, Rosenblum S, Ochoa J. Phentolamine sympathetic blocks mislead diagnosis. Soc Neurosci Abst 1991;17:107.

42. Verdugo R, Ochoa. High incidence of placebo responders among chronic neuropathic pain patients. Ann Neurol 1991;30:294.

43. Edmonds ME, Watkins PJ. Clinical presentations of diabetic autonomic failure. In: Bannister R, Mathias CJ, eds. Autonomic Failure. 3rd edn. Oxford: Oxford University Press, 1992:698-720.

44. Archer AG, Roberts VC, Watkins PJ. Blood flow patterns in painful diabetic neuropathy. Diabetologia 1984;2:563-7.

45. Flynn ME, Edmonds ME, Tooke JE, Watkins PJ. Direct measurement of capillary blood flow in the diabetic neuropathic foot. Diabetologia 1988;31:652-6.

46. Tack CJ, van Gurp PJ, Holmes C, Goldstein DS. Local sympathetic denervation in painful diabetic neuropathy. Diabetes 2002;51:3545-53.

47. Claus-Walker J, Valbona C, Carter RE, Lipscomb HS. Resting and stimulated endocrine function in human subjects with cervical spinal cord transection. J Chronic Dis 1971;24:193-207.

48. Claus-Walker J, Halstead LS. Metabolic and endocrine changes in spinal cord injury: II (section 1). Consequences of partial decentralization of the autonomic nervous system. Arch Phys Med Rehabil 1982;63:569-75.

49. DeBarge O, Christensen NJ, Corbett JL, Eidelman BH, Frankel HL, Mathias CJ. Plasma catecholamines in tetraplegics. Paraplegia 1974;12:44-9.

50. Frewin DM, Levitt M, Meyer SJ, Lo CC, Downey JA. Catecholamine responses in paraplegia. Paraplegia 1973;11:238-44. 
51. Guttmann L, Munro AF, Robinson R, Walsh JJ. Effect of tilting on cardiovascular responses and plasma catecholamines in spinal man. Paraplegia 1963;1:4-18.

52. Krum H, Brown DJ, Rowe PR, Louis WJ, Howes LG. Steady state plasma $[3 \mathrm{H}]$-noradrenaline kinetics in quadriplegic spinal cord injury patients. J Auton Pharmacol 1990;10:221-6.

53. Naftchi NE, Lowman EW, Sell GH, Rusk HA. Peripheral circulation and catecholamine metabolism in paraplegia and quadriplegia. Arch Phys Med Rehabil 1972;53:357-61.

54. Mathias CJ, Christensen NJ, Corbett JL, Frankel HL, Spalding JM. Plasma catecholamines during paroxysmal neurogenic hypertension in quadriplegic men. Circ Res 1976;39:204-8.

55. Mathias CJ, Christensen NJ, Corbett JL, Frankel HL, Goodwin TJ, Peart WS. Plasma catecholamines, plasma renin activity and plasma aldosterone in tetraplegic man, horizontal and tilted. Clin Sci Mol Med 1975;49:291-9.

56. Frankel HL, Michaelis LS, Golding DR, Beral V. Blood pressure in paraplegia. I. Paraplegia 1972;10:193-200.

57. Hachen HJ, Rossier AB, Bouvier CA, Ritschard J. Deficiency within extrinsic prothrombin activator system in patients with acute spinal cord injury. Paraplegia 1974;12:132-8.

58. Hannington-Kiff JG. Intravenous regional sympathetic blockade with guanethidine. Lancet 1974;1:1019-20.

59. Teasell RW, Arnold JM, Krassioukov A, Delaney GA. Cardiovascular consequences of loss of supraspinal control of the sympathetic nervous system after spinal cord injury. Arch Phys Med Rehabil 2000;81:506-16.

60. Chiou-Tan FY, Eisele SG, Song JX, Markowski J, Javors M, Robertson CS. Increased norepinephrine levels during catheterization in patients with spinal cord injury. Am J Phys Med Rehabil 1999;78:350-3

61. Mathias CJ, Frankel HL, Christensen NJ, Spalding JM. Enhanced pressor response to noradrenaline in patients with cervical spinal and transection. Brain 1976;99:757-70.

62. Mathias CJ, Frankel HL. The cardiovascular system in tetraplegia and paraplegia. In: Frankel HL, ed. Spinal Cord Trauma, Handbook of Clinical Neurology. Amsterdam: Elsevier Science Publishers, 1992:435-56.

63. Sato J, Perl ER. Adrenergic excitation of cutaneous pain receptors induced by peripheral nerve injury. Science 1991;251:1608-10.

64. Drummond PD, Finch PM, Gibbins I. Innervation of hyperalgesic skin in patients with complex regional pain syndrome. Clin J Pain 1996;12:222-31.

65. Kurvers H, Daemen M, Slaaf D, et al. Partial peripheal neuropathy and denervation induced adrenoceptor supersensitivity. Functional studies in an experimental model. Acta Orthop Belg 1998;64:64-70.

66. Bodmer CW, Lake D, Savage MW, Williams G. Hand vein responses to noradrenaline in normotensive patients with insulindependent diabetes mellitus and microalbuminuria: Effects of alpha-adrenoceptor blockade with doxazosin. Curr Med Res Opin 1999; 15:169-76.

67. Eichler HG, Blaschke TF, Kraemer FB, Ford GA, Blochl-Daum B, Hoffman BB. Responsiveness of superficial hand veins to alpha-adrenoceptor agonists in insulin-dependent diabetic patients. Clin Sci (Lond) 1992;82:163-8.
68. Capes S, Teasell R, Simon J, Finestone H, Arnold JMO. Alphaadrenoceptor hyperresponsiveness in painful diabetic neuropathy. [57th Annual Scientific Sessions of American Diabetes Association]. Boston, June 21 to 24, 1997.

69. Zeigler D, Lynch SA, Muir J, Benjamin J, Max MB. Transdermal clonidine versus placebo in painful diabetic neuropathy. Pain 1992;48:403-8.

70. Byas-Smith MG, Max MB, Muir J, Kingman A. Transdermal clonidine compared to placebo in painful diabetic neuropathy using a two-stage 'enriched enrollment' design. Pain 1995;60:267-74.

71. Arnold JMO, Feng QP, Delaney GA, Teasell RW. Autonomic dysreflexia in tetraplegic patients: Evidence for alpha-adrenoceptor hyperresponsiveness. Clin Auton Res 1995;5:267-70.

72. Erickson RP. Autonomic hyperreflexia: Pathophysiology and medical management. Arch Phys Med Rehabil 1980;61:431-40.

73. Lindan R, Joiner E, Freehafer AA, Hazel C. Incidence and clinical features of autonomic dysreflexia in patients with spinal cord injury. Paraplegia 1980;18:285-92.

74. Bors E. The challenge of quadriplegia: Some personal observations in a series of two hundred thirty-three cases. Bull Los Angel Neuro Soc 1956;21:105-23

75. Taiwo YO, Heller PH, Levine JD. Characterization of distinct phospholipases mediating bradykinin and noradrenaline hyperalgesia. Neuroscience 1990;39:523-31.

76. Baccalglini PJ, Hogan PG. Some rat sensory neurons in culture express characteristics of differentiated pain sensory cells. Proc Natl Acad Sci U S A 1983;80:594-8.

77. Taiwo YO, Goetzel EJ, Levine JD. Hyperalgesia onset latency suggests a hierarchy of action. Brain Res 1987;423:333-7.

78. Taiwo YO, Levine JD. Prostaglandin effects after elimination of indirect hyperalgesic mechanisms in the skin of rat. Brain Res 1989;492:397-9.

79. Levine JD, Taiwo YO, Collins SD, Tam JK. Noradrenaline hyperalgesia is mediated through interaction with sympathetic postganglionic neurone terminal rather than activation of primary afferent nociceptors. Nature 1986;323:158-60.

80. Gonzales RG, Goldyne ME, Taiwo YO, Levine JD. Production of hyperalgesic prostaglandins by sympathetic postganglionic neurons. J Neurochem 1989;53:1595-8.

81. Taiwo YO, Levine JD. Characterization of the arachindonic acid metabolic mediating bradykinin and norepinephrine hyperalgesia. Brain Res 1988;458:402-6.

82. Huygen FJPM, de Bruijn AGJ, Klein J, Zijlstra FJ. Neuroimmune alterations in teh complex regional pain syndrome. Eur J Pharmacol 2001;429:101-13.

83. Ghostine SY, Comair YG, Turner DM, Kassell NF, Azar CG. Phenoxybenzamine in the treatment of causalgia. Report of 40 cases. J Neurosurg 1984;60:1263-8.

84. Arner S. Intravenous phentolamine test: Diagnostic and prognostic use in reflex sympathetic dystrophy. Pain 1991;46:17-22.

85. Raja SN, Treede RD, Davis KD, Campbell JN. Systemic alphaadrenergic blockade with phentolamine: A diagnostic test for sympathetically maintained pain. Anesthesiology 1991;74:691-8.

86. Abram SE, Lightfoot RW. Treatment of long-acting causalgia with prazocin. Reg Anesth 1981;6:79-81.

87. Davis KD, Treede RD, Raja SN, Meyer RA, Campbell JN. Topical application of clonidine relieves hyperalgesia in patients with sympathetically-maintained pain. Pain 1991;47:309-17. 
Teasell and Arnold 


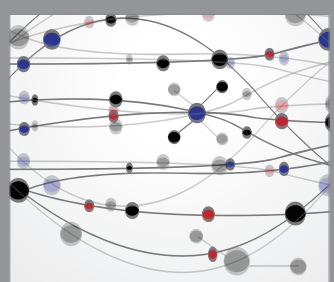

The Scientific World Journal
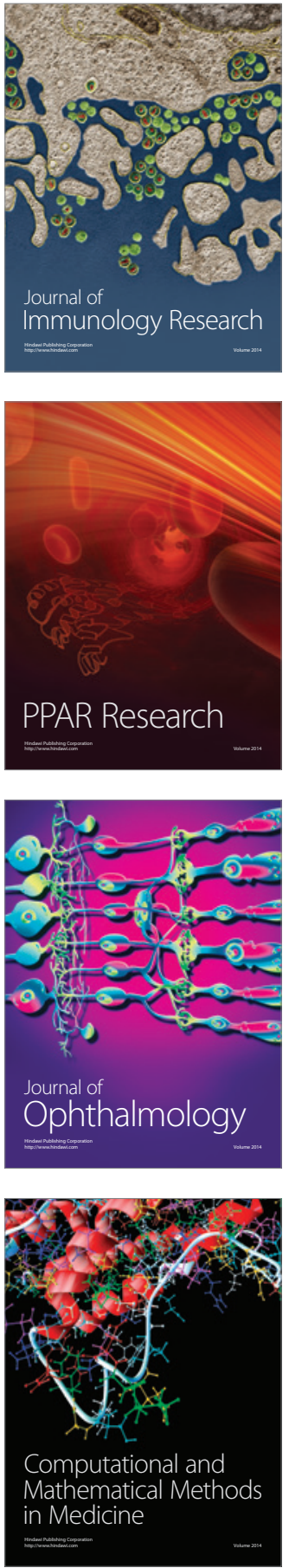

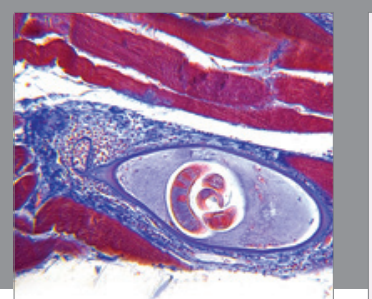

Gastroenterology Research and Practice

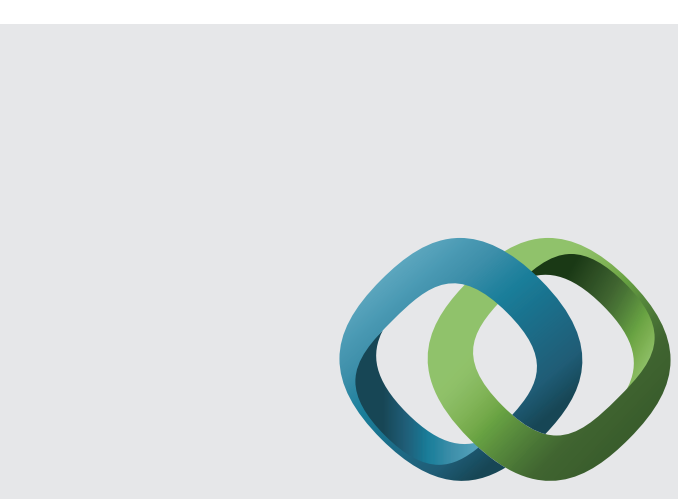

\section{Hindawi}

Submit your manuscripts at

http://www.hindawi.com
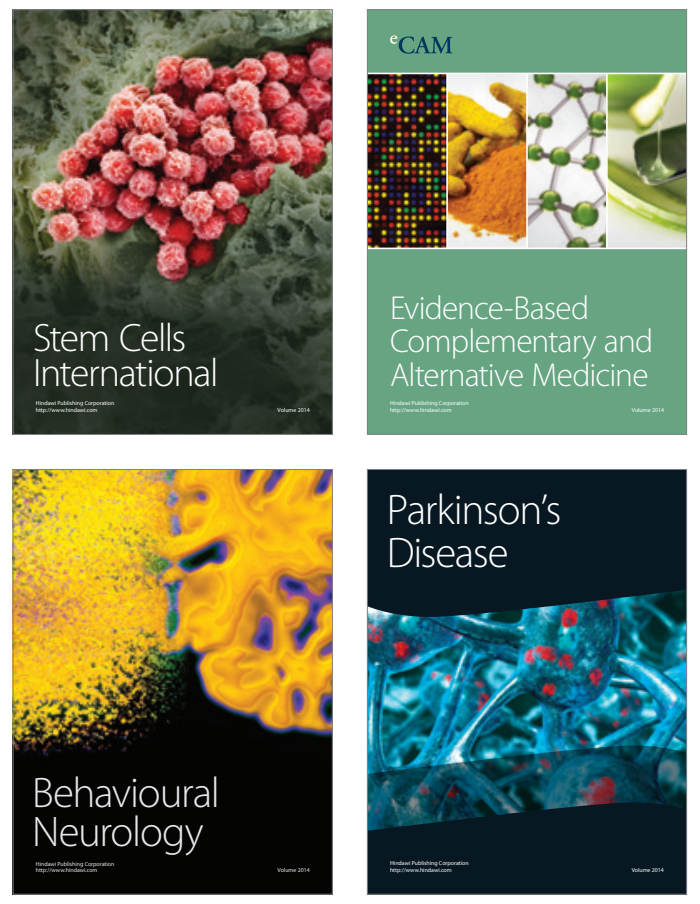
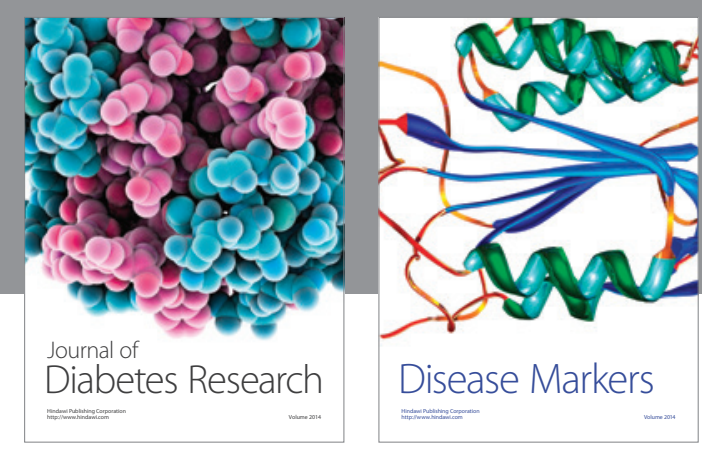

Disease Markers
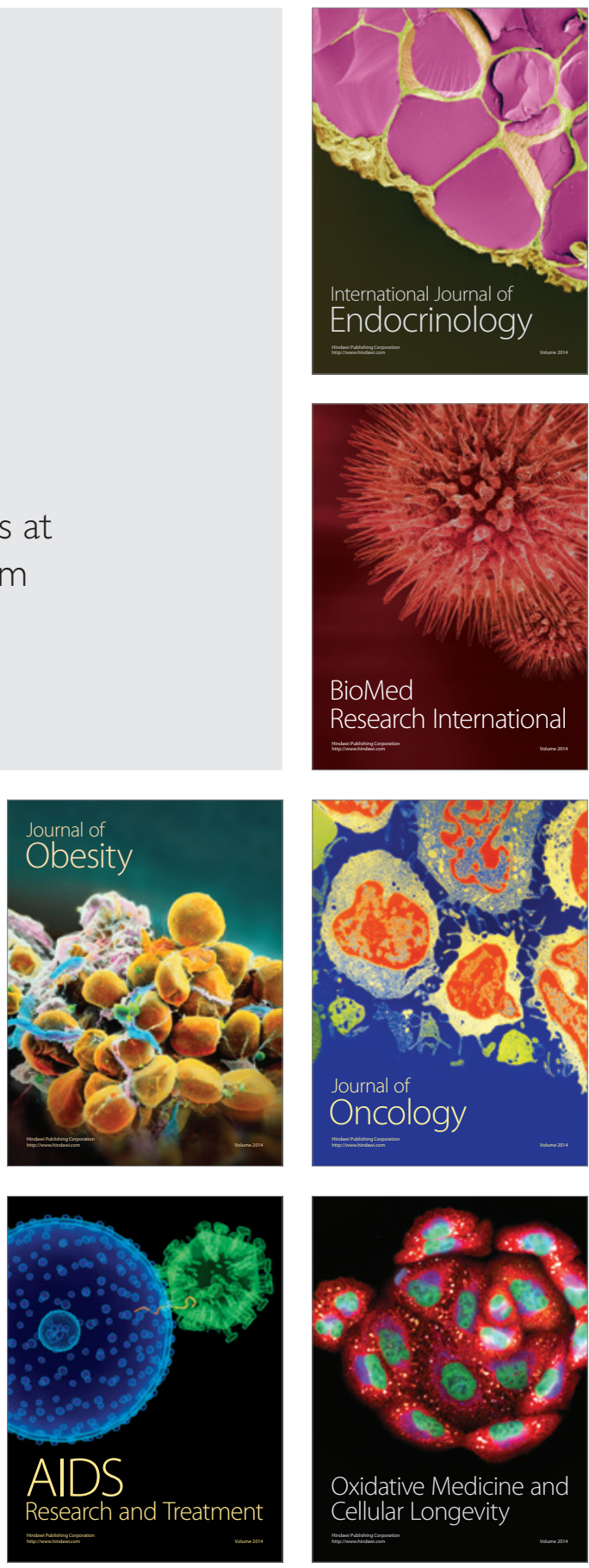